\title{
MODELLING OF CHEMICAL COMPOSITION OF WELD POOL METAL IN ARC METHODS OF WELDING
}

\author{
V.V. GOLOVKO and L.A. TARABORKIN \\ E.O. Paton Electric Welding Institute, NASU \\ 11 Kazimir Malevich Str., 03680, Kiev, Ukraine. E-mail: office@paton.kiev.ua
}

\begin{abstract}
Development of complex calculation algorithm based on system approach for numerical prediction of formation and growth of non-metallic inclusions in a weld metal is one of the important tasks in present time. One of significant blocks of it is a calculation estimation of weld metal chemical composition in arc methods of welding, which is of interest and being studied in present work. A procedure was proposed for calculation of content of weld pool melt in arc welding. The developed procedure is based on modelling of thermodynamics of interface interaction in metal-slag-gas-vapor phase system in a temperature range typical for weld pool existence in arc methods of welding. Predicted content of metal melt can be a basis for modelling of content, size, morphology and chemical composition of non-metallic inclusions in weld metal. 11 Ref., 3 Tables, 3 Figures.
\end{abstract}

Keywords: arc welding, weld pool, melt, thermodynamics, inclusions, slag, chemical composition, modelling, prediction

Development of high-strength low-alloy steels has become an outstanding achievement of ferrous metallurgy. Optimum combination of mechanical properties and efficiency of such steels production promoted their rapid development and wide implementation [1, 2]. Application of processes of refining and sparse alloying [3], in particular, provides for the possibility of achievement of such combination.

The main efforts of metallurgists were directed on production of metal with more refined grain structure, since grain size is one of the most significant factors determining service properties of low-alloy steels [4].

The experience of works on investigation of peculiarities of effect of non-metallic inclusions (NMI) on conditions of formation of structure of low-alloy steels and level of their service properties, which resulted in development of industrial technologies of production of current structural steels, indicate the relevance of investigation of effect of NMI on structure and mechanical properties of metal of welds from low-alloy steels of increased and high strength $[5,6]$.

In connection with it development of complex calculation algorithm based on system approach for numerical prediction of formation and growth of NMI in a weld metal is important and interesting problem.
One of significant blocks of it is a calculation estimation of weld metal chemical composition in arc methods of welding, representing absolute independent interest and being considered in this work.

Submerged arc welding is one of the comprehensive processes for complex description of pattern of cause-and-effect relationship in composition-structure-properties system. All know in present time aggregative states of the material, i.e. solid state, liquid, gas phase and plasma, participate in formation of weld metal. Metallurgical reactions in these phases and at interface take place in the temperature range approximately from 1000 to $10,000 \mathrm{~K}$. Duration of indicated reactions makes from $10^{-6} \mathrm{~s}$ to several seconds. Content of components in separate phases can significantly change in process of welding. Presence of high-gradient temperature and concentration field, typical for welding processes, make impact on character of interactions.

Additional difficulties, related with modelling of the processes of NMI formation, are induced by the fact that the main mass of inclusions is formed in molten metal of the weld pool [7], while information on chemical composition of solidified metal is used for calculations of their characteristics. At that, content of alloying and impurity elements in steel, appearing

\footnotetext{
${ }^{*}$ This issue represents several papers (pp. 12-16), prepared by members of the PWI Department «Physical-chemical processes in welding arc» devoted to the memory of developer and permanent chief of the Department Prof. Igor K. Pokhodnya. The papers highlight development of some scientific ideas and technological approaches to solution of problems for providing high quality of welding consumables, which are typical for developments of the PWI. These directions remain priority topics of the Department.
} 
as a result of interaction between metallic and slag phases in a course of melt existence, are not considered. It can significantly effect content and chemical composition of inclusions [8]. Calculation estimation based on data on weld pool, i.e. on content of metal in a temperature range above the temperature of start of its solidification, is necessary in order to get objective information on content, morphology and size of NMI.

Step-by-step method is used to study the metallurgical peculiarities of submerged arc welding for the purpose of simplification of stated problem. Conditional schematic division of weld metal formation process on three zones, namely reaction zone at droplet stage (from iron boiling temperature 3134 to $10000 \mathrm{~K}$ ); reaction zone in area of high temperatures (from 2500 to $3134 \mathrm{~K}$ ); and reaction zone in area of low temperatures (from 1800 to $2500 \mathrm{~K}$ ), is taken for this.

Three main calculation schemes were formed in accordance with this division and used for investigation of metallic, slag and gas phase, respectively.

Today the single generally available method for calculation of activities in metallic phase, which is provided by numerical values of parameters for the most elements applied in metallurgy, is Wagner (decomposition) method [9], therefore it was taken as basic one.

However, Wagner method does not include thermodynamic requirements to state equation. At the same time, a theory of subregular solutions, representing sufficiently simple model, satisfying specific thermodynamic requirements, and having significant advantages in description of multicomponent systems, is not provided with parameter numerical values.

Joint application of theory of subregular solutions with calculation of coefficients of distribution on parameters of Wagner interaction in thermodynamic model of distribution of elements between metal, slag and gaseous phase provides for higher correlation of calculation and experimental data in all area of compositions.

Model of collective electrons of Ponomarenko seems to be the best for calculation of activities in slag phase. It considers slags as a solution, components of which are the Periodic Table elements, that allows calculating their activities independently. Therefore, calculation modelling of metal-slag system uses a procedure for evaluation of thermodynamic functions of the slag as phase with collective electrons (method of collective electrons) [10], provided with all necessary numerical parameters and allowing calculating activity of the slag phase components as well as, in the most general case, taking into account nonstoichiometry of all phases.
Thermodynamic equilibrium reactor (TER) was used for calculation of gaseous phase. It is designed for calculation of chemical equilibrium in multi-component heterogeneous systems [11]. A basis of algorithm of TER program is a general principle of entropy maximum $S$ for calculation of chemical and phase composition and corresponding program works in Chemical WorkBench program package (Kinetic Technologies) Company, Moscow, Russia).

According to indicated principle, an equilibrium state is characterized by uniform distribution of thermodynamic parameters in studied volume, and chemical composition corresponds to maximum of possibility of distribution of energy levels for macroparticles:

$$
S=S_{\max } \text { at } M_{j}=\text { const } \quad U=\text { const } ;=\text { const, }
$$

where $M_{j}$ is the weight of $j$-th chemical element; $U$ is the function of internal energy; $v$ is the specific volume.

Corresponding state equations for calculation parameters of thermodynamic equilibrium are embedded based on the fact that entropy of multicomponent system consists of entropy of different components and phases, i.e. components of neutral gas and ions type, having ideal gas properties, and components which formed pure condensed phases (solid or liquid state) and condensed solutions. In particular, entropy of gaseous phase is determined on formula

$$
S_{\mathrm{g}}=\sum_{i=1}^{k}\left(S_{i}^{0}-R \ln \frac{R T}{v} M_{i}\right) M_{i},
$$

where $S_{i}^{0}$ is the standard absolute entropy; $M_{i}$ is the number of moles of $i$-th component per $1 \mathrm{~kg}$ of system; $p=R T M_{i} / v$ of pressure of $i$-th component.

Entropy of components, forming separate pure condensed phase in accordance with additivity concept, equals

$$
S_{\mathrm{c}}=\sum_{n=1}^{N_{\mathrm{c}}} S_{n}^{0} M_{n},
$$

where $S_{n}^{0}$ is the entropy of condensed phase on 1 mole of a substance; $M_{n}$ is the number of moles per $1 \mathrm{~kg}$ of the condensed phase; $N$ is the total number of separate condensed phases.

Parameters of equilibrium state are found as values of all variables of the studied system, including number of moles of components, under condition of entropy maximum and additional limitations on parameters imposed by mass conservation law. Procedure for calculation of target parameters is based on method of Lagrange using Newton-Raphson method for solving a set of non-linear equations [11]. 


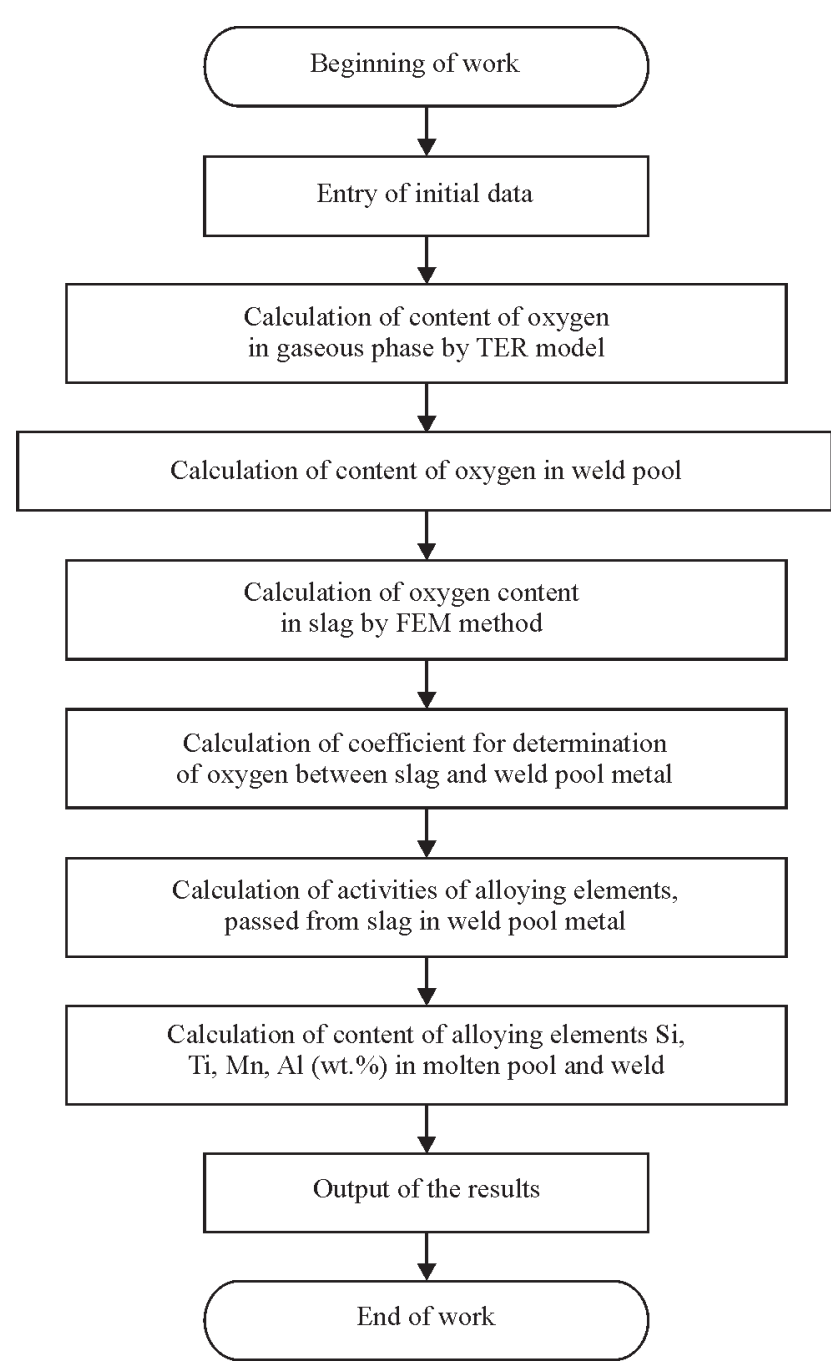

Figure 1. Block-diagram of algorithm of program for calculation of chemical composition of weld pool metal in arc methods of welding

Developed calculation scheme allows numerical evaluation of weight fraction of alloying elements in the weld pool and weld metal in submerged arc welding based on data on chemical composition of flux, wire and steel to be welded.

The following values are used as input parameters:

- chemical composition of flux, presented in oxide-slat form, moreover it is supposed that initial composition of the slag system matches with flux composition and contains all or some of mentioned components: $\mathrm{SiO}_{2}, \mathrm{Al}_{2} \mathrm{O}_{3}, \mathrm{CaF}_{2}, \mathrm{MgO}, \mathrm{MnO}, \mathrm{TiO}_{2}$, $\mathrm{CaO}$, sum of percent content of which shall equal $100 \%$;

- weight fractions (\%) of alloying components $\mathrm{Si}$, $\mathrm{Ti}, \mathrm{Mn}, \mathrm{Al}$ as well as oxygen in steel and welding wire;

- portion of base metal in weld pool metal;

- temperature characteristics of studied process.

Corresponding output (resultant) variables of calculation are as follows:

- weight fraction of oxygen in weld pool;

- weight fraction of alloying elements $\mathrm{Si}, \mathrm{Ti}, \mathrm{Mn}$, $\mathrm{Al}$ in weld pool;
- weight fraction of alloying elements $\mathrm{Si}, \mathrm{Ti}, \mathrm{Mn}$, $\mathrm{Al}$ in weld metal.

Thus, the algorithm of calculation evaluation includes the following steps (Figure 1):

1. Determination on calculation TER of oxygen content in gaseous phase, which is entered as a result of reaction between slag and welding arc. A peculiarity of this stage is the fact that Chemical WorkBench program, among formally thermodynamically probable products of chemical reactions in droplet stage, provides for significant number of such, which on practice (due to extraordinarily small corresponding contents) can be eliminated in further calculations. Therefore, received list of reaction products is subjected to revisions and corresponding significant reduction;

2. Calculation of content of oxygen $[\mathrm{O}]$ in the weld pool, for which purpose to received in item 1 value, firstly, it is necessary to add fraction, coming from wire (obtained intermediate sum corresponds to oxygen content in droplet), and then add to computed value content of oxygen in base metal taking into account portion of base metal in weld pool formation. As a rule, resultant $[\mathrm{O}]$ value does not exceed $0.1 \mathrm{wt} . \%$ and, therefore, it can be equaled to oxygen activity $\left[a_{\mathrm{O}}\right]$ in the weld pool;

3. Calculation of oxygen content in slag, for which it is sufficient to calculate oxygen activity $\left(a_{\mathrm{O}}\right)$ in the slag on FEM according to work [10];

4. Determination of coefficient of oxygen distribution $L_{\mathrm{O}}$ between slag and weld pool metal by formula $L_{\mathrm{O}}=\left(a_{\mathrm{O}}\right) /\left[a_{\mathrm{O}}\right]$

5. Calculation of activity of alloying elements $\left[a_{\mathrm{Me}}\right]$, passing from slag in weld pool metal by formula $\left[a_{\mathrm{Me}}\right]=\left(a_{\mathrm{Me}}\right) / L_{\mathrm{Me}}$, where for simplicity it can be taken that coefficients of distribution $L_{\mathrm{Me}}$ of alloying elements between slag and weld pool approximately equals to found in item 4 coefficient $L_{\mathrm{O}}$;

6. Calculation of content of each alloying element $\mathrm{Si}, \mathrm{Ti}, \mathrm{Mn}, \mathrm{Al}$ (wt.\%) in weld pool and weld as sum of its contents in droplet, in base metal (taking into account its portion) and alloying elements, passing from slag phase (see item 5).

Computer realizing of described algorithm was carried out in object-oriented media for visual programming Delphi 7. Developed computer program works under the operating system Windows XP.

After launching the program displays a form (Figure 2) which contains fields and tables for input and output of data, provided in algorithm description. The program allows carrying out multi-choice calculations for fixed set of values of input variables, since allows performing new calculation without complete cleaning of all form, i.e. after change of some (even 
Table 1. Composition of fluxes used in investigations and their basicity, wt. $\%$

\begin{tabular}{|c|c|c|c|c|c|}
\hline $\begin{array}{c}\text { Flux } \\
\text { number }\end{array}$ & $\mathrm{MgO}$ & $\mathrm{Al}_{2} \mathrm{O}_{3}$ & $\mathrm{SiO}_{2}$ & $\mathrm{CaF}_{2}$ & $B I$ \\
\hline 3 & 40 & 30 & 15 & 15 & 1.83 \\
\hline 9 & 20 & 35 & 20 & 25 & 1.20 \\
\hline 14 & 20 & 40 & 25 & 15 & 0.78 \\
\hline 19 & 35 & 40 & 0 & 25 & 3 \\
\hline 20 & 35 & 0 & 40 & 25 & 1.50 \\
\hline
\end{tabular}

one) of entered values. Check of adequacy of the developed calculation evaluation was carried out in arc welding using agglomerated fluxes, content of which was built on $\mathrm{MgO}-\mathrm{SiO}_{2}-\mathrm{Al}_{2} \mathrm{O}_{3}-\mathrm{CaF}_{2}$ system. Scheme of weld formation, used for evaluation of portion of base metal in weld pool, is given in Figure 3.

Oxygen potential of fluxes was changed due to change of $\mathrm{MgO} / \mathrm{SiO}_{2}$ relationship for investigation of possibility of prediction of its effect on conditions of NMI formation.

Submerged arc welding was carried out in combination with welding wire Sv-08GA of $4 \mathrm{~mm}$ diameter in accordance with the requirements of ISO 14171:2000. Butt joints from low-alloy steel of 10KhSND grade of $25 \mathrm{~mm}$ thickness with $60^{\circ}$ beveling and $20 \mathrm{~mm}$ gap in weld root were produced in course of experiments. Templates for production of mircosections for metallographic investigation were cut out from metal of the last layer, which was located in the middle of the upper layer.

Metallographic investigations were carried out on transverse microsections, cut out from welded joints. Quantitative analysis of NMI and determination of general contamination of the weld with inclusions was performed with the help of optical microscope Neophot-30 (Carl Zeiss Jena, Germany), equipped with high resolution digital camera. In particular, distribution of inclusions on size was determined using images of $2592 \times 1944$ pixels size. Calculation of amount of inclusion in each specimen on size group, i.e. from minimum to maximum size, was carried out on set program. Analysis of NMI chemical composition were performed on electron microscope JSM-35 (Japan) with the help of energy dispersion spectrometer INCA-350 (Great Britain) «point by point» with the purpose of elimination of background radiation.

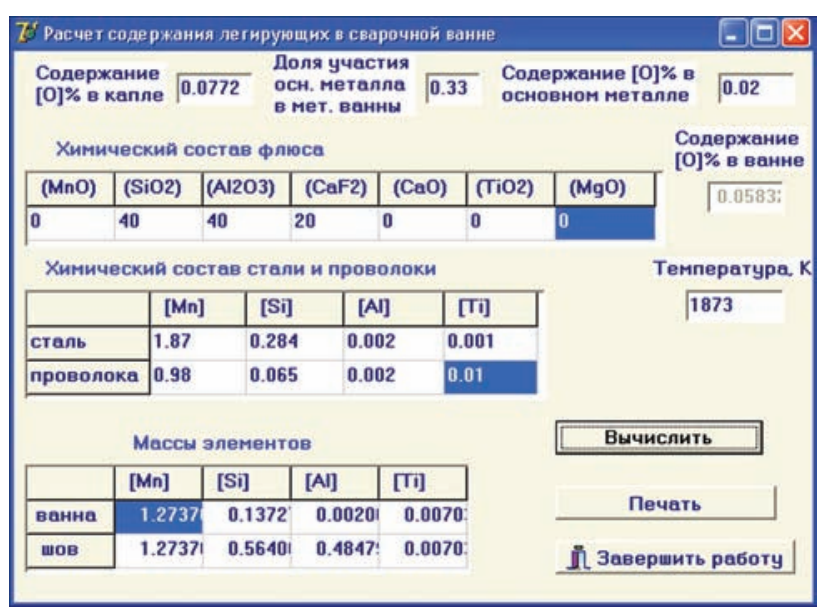

Figure 2. Window of program for numerical modelling of transfer of alloying elements in molten pool and weld in submerged arc welding

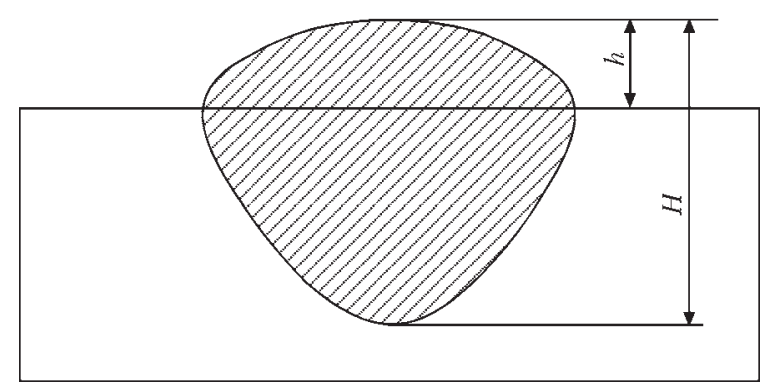

Figure 3. Scheme of weld formation

Compositions of experimental fluxes (Table 1; in general it was 20 variants) were calculated in accordance with optimum mathematical experimental plan. Values of their basicity were calculated by formula

$$
\mathrm{BI}=\frac{\mathrm{MgO}+\mathrm{CaF}_{2}}{\mathrm{SiO}_{2}+0.5 \mathrm{Al}_{2} \mathrm{O}_{3}} .
$$

Table 2 provides for the results of correlation of calculated contents of oxygen and alloying elements in the weld metal with data on their determination in specimens of deposited metal obtained in welding using pilot fluxes. Content of these elements is given in Table 3 .

Observed differences between calculation and experimental data are caused by processes of formation of NMI in wed metal in two-phase zone, located in interdendritic volumes at temperatures below equilibrium solidification temperature. Besides, they one more time underline that prediction of content and composition of NMI in metal of formed weld can not

Table 2. Calculation (in weld pool) and experimental (in weld metal) content of elements

\begin{tabular}{|c|c|c|c|c|c|c|c|c|}
\hline \multirow{2}{*}{$\begin{array}{c}\text { Flux } \\
\text { number }\end{array}$} & \multicolumn{4}{|c|}{ Experimental data, wt.\% } & \multicolumn{4}{c|}{ Calculation data, wt.\% } \\
\cline { 2 - 10 } & $\mathrm{O}$ & $\mathrm{Mn}$ & $\mathrm{Al}$ & $\mathrm{Si}$ & $\mathrm{O}$ & $\mathrm{Mn}$ & $\mathrm{Al}$ & $\mathrm{Si}$ \\
\hline 3 & 0.035 & 0.71 & 0.0108 & 0.637 & 0.1426 & 1.1474 & 0.2025 & 0.8445 \\
\hline 9 & 0.029 & 0.67 & 0.0128 & 0.668 & 0.0548 & 1.1904 & 0.3877 & 0.6750 \\
\hline 14 & 0.046 & 0.65 & 0.0154 & 0.676 & 0.0618 & 1.1904 & 0.4312 & 0.7145 \\
\hline 20 & 0.028 & 0.63 & 0.0080 & 0.688 & 0.0581 & 1.1818 & 0.4059 & 0.8680 \\
\hline 19 & 0.024 & 0.75 & 0.0182 & 0.583 & 0.3370 & 1.1732 & 0.0020 & 0.4831 \\
\hline
\end{tabular}


Table 3. Content of oxygen and alloying elements in base metal and wire

\begin{tabular}{|c|c|c|c|c|}
\hline \multirow{2}{*}{ Material } & \multicolumn{4}{|c|}{ Content, wt.\% } \\
\cline { 2 - 5 } & $\mathrm{O}$ & $\mathrm{Mn}$ & $\mathrm{Al}$ & $\mathrm{Si}$ \\
\hline Base metal & 0.005 & 0.87 & 0.002 & 0.280 \\
\hline Wire & 0.016 & 0.98 & 0.002 & 0.065 \\
\hline
\end{tabular}

be based on data on its chemical composition, being final product of all processes and reactions which took place. Application of calculation data on composition of «virtual» weld pool is more adequate for this purpose.

The similar approaches were performed for other alloying elements (Ti, Si, Al). Thus, the calculation data on content of alloying elements and oxygen in weld metal, obtained with the help of described model, can serve as initial values for modelling integral composition of NMI, such as morphology as well as composition of separate phases, forming these inclusions, based on objective information on initial conditions of their formation.

Proposed approach and developed calculation scheme can be distributed on other methods of arc fusion welding (with coated electrodes, flux-cored wire), which includes metallic, vapor-gas and slag phases.

\section{Conclusions}

The method was proposed for calculation of composition of weld pool metal melt. Developed procedure is based on modelling of thermodynamics of interface interaction in metal-gas-vapour phase system in a temperature range typical for existence of weld pool in arc methods of welding. The predicted composition of metal melt can serve as initial base for further modelling of content, size, morphology and chemical composition of non-metallic inclusions in weld metal.

1. Weng, Y. (2003) Microstructure refinement of structural steel in China. ISIJ Int., 43(11), 1675-1682.

2. Borovikov, A.V. (2003) Production of straight-seam large-diameter pipes made of steel of strength class X80. Metallurgist, Vol. 47, 9-10.

3. Kim, Y.M., Kim, S.K., Lim, Y.J. et al. (2002) Effect of microstructure on the yield ratio and low temperature toughness of line pipe steels. ISIJ Int., 42(12), 1571-1577.

4. Shukla, R., Das, S.K., Kumar, B.R. et al. (2012) Ultralow carbon, thermomechanically controlled processed microalloyed steel: Microstructure and mechanical properties. Metallurg. and Mater. Transact. A, 43(12), 4835-4845.

5. Park, J.S., Lee, C., Park, J.H. (2012) Effect of complex inclusion particles on the solidification structure of $\mathrm{Fe}-\mathrm{Ni}-$ Mn-Mo alloy. Ibid., B, 43(12), 1550-1557.

6. Sarma, D.C., Karasev, A.V., Jonson, P.G. (2009) On the role of nonmetallic inclusions in the nucleation of acicular ferrite in steels. ISIJ Int., 49(7), 1063-1074.

7. Babu, S.S. (2009) Thermodynamic and kinetic models for describing microstructure evolution during joining of metals and alloys. Int. Materials Rev., 6, 333-367.

8. Zinngrebe, E., Van Hoek, C., Visser, H. et al. (2012) Inclusion population evolution in Ti-alloyed Al-killed steel during secondary steelmaking process. ISIJ Int., 52(1), 52-61.

9. Jung In-Ho, Decretov, S.A., Pelton, A.D. (2004) Computer application of thermodynamic databases to inclusion engineering. Ibid., 44(3), 527-536.

10. Grigoryan, V.A., Stomakhin, A.Ya., Ponomarenko, A.G. (1989) Physical-chemical calculations of electric steelmaking processes. Moscow: Metallurgiya.

11. (2007) CHEMICAL WORKBENCH Vers. 3.5: Description of reactor models. Moscow: Kinetic Technologies. 